\title{
ANALISA METODE PERBAIKAN TANAH LUNAK DAN KOHESIF
}

\author{
Irza Ahmad
}

\begin{abstract}
Abstrak
Tujuan penelitian ini adalah untuk mendapat keuntungan dari beberapa macam metode perbaikan tanah lunak dan kohesif. Hal ini sangat penting sehubungan dengan perencanaan pondasi. Pondasi akan kokoh dan kuat bila terletak pada tanah yang mempunyai kemampuan atau daya dukung yang mencukupi bagi beban yang diterima. Jadi untuk tanah yang lunak dan kohesif perlu diperbaiki terlebih dahulu sebelum melakukan pondasi di atasnya.

Mengingat pengaruh metode-metode itu berbeda-beda maka kita harus mengetahui metode yang mempunyai pengaruh metode paling banyak dan yang paling sedikit. Adapun pengaruh metode tersebut baik terhadap deformasi geser, pengaruh liquefaction, jumlah total pengurangan penurunan, pengurangan kekuatan, dan lain sebagainya.

Hasil yang diperoleh dari penelitian ini adalah metode tiang pasir padat menunjukkan yang paling baik untuk perbaikan tanah lunak di samping masih mempunyai hasil sampingan yaitu pengurangan penurunan, pembelian ketahanan gelincir dan pencegahan terhadap liquefaction.
\end{abstract}

Keyword : perbaikan tanah

\section{PENDAHULUAN}

Untuk mendirikan bangunan, baik gedung, jembatan, jalan raya, pelabuhan, semuanya membutuhkan pondasi yang kuat. Agar diperoleh pondasi yang kuat, pondasi tersebut haruslah terletak pada tanah yang mampu menahan beban pondasi. Pada kenyataannya tanah yang ditemukan di lapangan tidak semuanya baik menerima beban. Misalnya pada tanah lunak, tidak mampu menerima beban, sehingga tanah lunak tersebut perlu diperbaiki agar dapat membangun pondasi.

Perbaikan tanah lunak atau soil improvement merupakan salah satu hal yang sangat penting dan mendapat perhatian para ahli geoteknik. Perhatian tersebut disebabkan oleh kebutuhan akan lahan yang harus dapat menampung tuntutan pembangunan, dan perkembangan penduduk. Banyak diantara lahan-lahan yang tersedia bagi pembangunan tersebut perlu mendapat pengolahan secara teknis terlebih dahulu, agar memenuhi

Irza Ahmad, Ir.,MT.

Staf Pengajar Jurusan Teknik Sipil

Fakultas Teknik

Universitas Negeri Jakarta, 13220 
persyaratan teknis, keamanan, dan kelestarian lingkungan. Sebagian besar dari lahan yang tersedia itu dapat berupa lapisan tanah lunak, bahkan daerah rawa, yang jika dibangun tanpa pengolahan melalui cara perbaikan tanak, akan merusak bangunan di atasnya sehingga tidak tahan lama.

Karena hal tersebut di atas menyebabkan para ahli melakukan penelitian mengenai perbaikan tanak lunak yang kemudian menghasilkan beberapa metode untuk mengatasinya. Adapun metode perbaikan tanah terdiri dari perbaikan tanah pondasi berpasir lepas, perbaikan lapisan tanah dasar yang lunak kohesif dan kohesif serta perbaikan stabilitas lapisan dangkal.

Dalam penelitian ini dilakukan studi literatur mengenai perbaikan tanah lunak dengan beberapa metode.

\section{Perbaikan Tanah}

Tanah tempat pondasi dibangun terdiri dari berlapis-lapis. Ada lapisan yang keras dan ada lapisan yang lunak. Untuk lapisan yang lunak umumnya terdiri dari tanak yang sebagian besar mempunyai butir-butir yang sangat halus seperti, lempung atau lanau, sehingga dalam lapisan lunak makin muda akumulasinya makin tinggi letak muka air tanahnya. Hal tersebut menyebabkan lapisan muda kurang mengalami pembebanan sehingga sifat mekanismenya buruk dan tidak mampu memikul beban.

Sifat lapisan tanah adalah gaya gesernya kecil, kemampatannya yang besar, dan koefisien permeabilitas yang kecil serta bila kena air akan terjadi liquefaction. Bila pembebanan kontruksi melampaui daya dukung batas, maka akan terjadi kerusakan tanah dasar untuk pondasi. Meskipun intensitas beban itu kurang dari daya dukung kritis, dalam jangka waktu yang lama besarnya penurunan akan meningkat yang akhirnya akan mengakibatkan keruntuhan.

Gejala kerusakan tanah pondasi atau penurunan tambahan bukan hanya akan menyebabkan konstruksi itu tidak berfungsi semestinya, melainkan dapat mengakibatkan permukaan tanah disekeliling konstruksi itu naik atau turun, atau penurunan muka air tanah atau penggenangan air di tempat konstruksi. 
Hal ini dapat mengakibatkan kerusakan pada keseluruhan bangunan yang disebabkan, terjadi konsolidasi yang besar pada tanah pondasi. Konsolidasi ini tidak dapat dicegah dan akan berjalan dalam waktu yang lama.

Untuk mencegah hal yang tidak diinginkan, maka perlu diadakan perbaikan tanah lunak dengan beberapa metode yang ada, yang sesuai dengan kondisi tanah dan karakteristik tanah lunak. Dalam perbaikan tanah lunak ada masalah-masalah pada pekerjaan seperti penurunan, daya dukung, kepadatan, pekerjaan galian dan lain sebagainya. Perbaikan karakteristik tanah yang akan diadakan dengan maksud untuk memperbaiki kondisi tanah pondasi itu, dapat dibagi sebagai berikut :

1. Perbaikan karakteristik geseran bertujuan untuk menghindarkan kerusakan tanah pondasi, menghindarkan deformasi geseran dan pengurangan tekanan tanah.

2. Perbaikan kemampatan bertujuan untuk memperpendek waktu penurunan karena konsolidasi dan menghindarkan penurunan residual.

3. Pengurangan permeabilitas bertujuan untuk menghindarkan bocoran.

4. Perbaikan karakteristik yakni bertujuan untuk mengurangi vibrasi dan menghindarkan liquefaction sewaktu terjadi gempa bumi.

Peningkatan kekuatan geser tanah dapat diadakan dengan salah satu tindakan sebagai : perbaikan pengikatan antara butir-butir untuk meningkatkan kohesi antara butir.

Pada tanah lunak kohesif, perbaikan karakteristik geseran diadakan dengan meningkatkan kerapatan tanah yang dapat dicapai dengan membuat drainasi sehingga kohesi tanah meningkat. Sebaliknya untuk tanah berpasir yang lepas, karakteristik geseran dapat ditingkatkan dengan metode pemadatan yang akan meningkatkan tahanan geser tanah itu.

Untuk perbaikan karateristik lapisan tanah yang dangkal yang tidak cukup gradasinya hanya dapat diadakan dengan mengubah bentuk gradasi sehingga kerapatannya meningkat atau perbaikan dengan menambahkan bahan stabilitas. Perbaikan kemampatan tanah diadakan dengan meningkatkan kekokohan kerangka butir atau dengan mengusahakan pengurangan volume pori supaya deformasi tanah itu tetap. Sehingga bila terjadi deformasi oleh konsolidasi tanah pondasi pada tanah kohesif haruslah dilaksanakan terlebih dahulu dengan beban yang cukup besar, agar penurunan residual sesudah bangunan dilaksanakan akan dapat direduksi seminimum mungkin. 
Untuk meningkatkan kekuatan antar butir, dapat digunakan bahan tambahan atau injeksi bahan pengikat yang dapat memperkuat kaitan antar butir-butir atau membuat air dalam pori itu menjadi beku. Perpendekan waktu penurunan (time of settlement) oleh konsolidasi dapat dilaksanakan dengan memperpendek jarak drainasi yakni dengan memasang lapisan permeabel buatan atau dengan gaya elektrokimia. Penambahan dan injeksi bahan stabilisasi atau metode pembekuan untuk memperbaiki kemampatan tanah adalah berguna juga untuk menutup rembesan air atau untuk menambah kekedapan air.

Prinsip dasar perbaikan tanah pondasi itu pada dasarnya adalah memperbaiki karakteristik mekanis tanah. Ada dua metode yang digunakan untuk memperbaiki tanah pondasi yakni metode yang meningkatkan kerapatan tanah dengan pemadatan tanah atau mengeluarkan air yang terkandung dalam tanah dan metode yang mengkonsolidasi tanah dengan penambahan atau injeksi bahan stabilisasi. Dewasa ini kedua metode ini yang sering digunakan dalam usaha-usaha perbaikan tanah pondasi.

Metode perbaikan yang diterapkan pada lapisan yang agak dangkal berbeda dengan metode yang diterapkan pada lapisan yang agak dalam. Meskipun kedua metode ini secara teknis berbeda satu dengan yang lain, pada dasarnya metode-metode ini adalah sama karena stabilisasi itu dicapai oleh peningkatan kerapatan atau konsolidasi tanah.

Di samping metode perbaikan karakterisitik mekanis dari tanah, maka diantara metode-metode yang dipakai untuk perbaikan tanah pondasi terdapat metode pergantian tanah yang kurang baik dengan tanah yang baik atau metode yang memperkuat timbunan tanah sebagai imbangan berat (counterweight) memperpanjang jangka pelaksanaan sehingga terjadi pengaruh pemampatan dengan perlahan-lahan tanpa menerapkan perbaikan tanah yang sebenarnya.

Mengingat pengaruh metode itu berbeda, maka metode yang digunakan harus sesuai dengan karakteristik lapisan tanah lunak, jenis bangunan, dan metode pelaksanaan. Suatu tindakan perbaikan itu umumnya tidak hanya menghasilkan suatu hasil perbaikan, melainkan beberapa hasil perbaikan lain, disamping diperoleh tujuan utamanya. Sering juga secara bersama diperoleh hasil sekundernya. Umpamanya, suatu drainasi vertikal yang terutama ditujukan untuk mempercepat penurunan konsolidasi juga diperoleh hasil sampungan atau sekunder yaitu meningkatkan kekuatan tanah tersebut. 


\section{METODOLOGI}

Dalam pembahasan kerangka pemikiran telah dikemukakan bahwa penelitian ini bermaksud mencari saling hubungan antara variabel, khususnya variable bebas yang berupa metode perbaikan tanah, dan variable terikat yaitu karakteristik tanah.

Sebagai persiapan penelitian, dibahas kepustakaan yang berhubungan dengan karakteristik tanah.

Pada tahap pertama penelitian dilakukan penjabaran karakteristik tanah melalui analisis sintesis. Data yang diperoleh dibandingkan satu dengan yang lain dari data kepustakaan, dan atas dasar perbandingan itu dapat disusun kategori dan indikator khusus perbaikan tanah.

Meskipun tahap penelitian dapat dipisahkan, namun menurut Glaser dan Strauss, proses pengambilan kesimpulan atau pengembangan teori merupakan proses yang senantiasa berkembang (continously growing process) dengan analisis yang berjalan majumudur (back and forth) (Barney).

Ikhtisar Metodologi Penelitian

\begin{tabular}{|c|c|c|c|c|c|c|c|c|c|c|}
\hline No & $\begin{array}{c}\text { Metode } \\
\text { Pelaksanaan }\end{array}$ & $\begin{array}{l}\text { Timbulnya } \\
\text { Penurunan } \\
\text { konsolidasi }\end{array}$ & $\begin{array}{c}\text { Jumlah total } \\
\text { pengurangan } \\
\text { penurunan }\end{array}$ & $\begin{array}{l}\text { Batasan } \\
\text { deformasi } \\
\text { geser }\end{array}$ & $\begin{array}{c}\text { Batasan } \\
\text { pengurangan } \\
\text { kekuatan }\end{array}$ & $\begin{array}{c}\text { Timbulnya } \\
\text { kenaikan } \\
\text { kekuatan } \\
\text { efektif }\end{array}$ & $\begin{array}{c}\text { Pemberian } \\
\text { ketahanan } \\
\text { gelincir }\end{array}$ & $\begin{array}{c}\text { Pencegaha } \\
n \text { terhadap } \\
\text { liquefaction }\end{array}$ & Tujuan & Teknik \\
\hline 1 & $\begin{array}{l}\text { Perbaikan } \\
\text { permukaan }\end{array}$ & & & & & & & & \multirow{8}{*}{$\begin{array}{c}\text { Klasifi- } \\
\text { kasi } \\
\text { konsep } \\
\text { dalam } \\
\text { Indika-tor }\end{array}$} & \multirow[t]{8}{*}{ analisis } \\
\hline 2 & Perpindahan & & & & & & & & & \\
\hline 3 & $\begin{array}{l}\text { Imbangan } \\
\text { berat }\end{array}$ & & & & & & & & & \\
\hline 4 & Pembebanan & & & & & & & & & \\
\hline 5 & $\begin{array}{l}\text { Drainase } \\
\text { vertikal }\end{array}$ & & & & & & & & & \\
\hline 6 & $\begin{array}{l}\text { Tiang pasir } \\
\text { padat }\end{array}$ & & & & & & & & & \\
\hline 7 & Tiang kapur & & & & & & & & & \\
\hline 8 & $\begin{array}{l}\text { Pencampuran } \\
\text { lapisan dalam }\end{array}$ & & & & & & & & & \\
\hline
\end{tabular}




\section{HASIL DAN PEMBAHASAN}

Berdasarkan studi literatur mengenai perbaikan tanah lunak dan kohesif diperoleh pengaruh dari metode-metode yang ditinjau :

\section{Metode perbaikan permukaan}

Metode perbaikan permukaan yang terbagi 3 macam ini yaitu metode drainasi permukaan, betasan deformasi geser dan hasil sampingan dari metode perbaikan permuakaan yaitu batasan pengurangan kekuatan, timbulnya kenaikan tekanan, pemberian ketahanan gelincir, dan pencegahan terhadap liquefaction.

\section{Metode perpindahan}

Pengurangan metode perpindahan ini terhadap tanah yang akan diperbaiki adalah perubahan sifat tanah yaitu memberikan ketahanan geser yang lebih baik. Hal ini disebabkan mutu tanahnya telah lebih baik sehingga faktor keamanan bertambah dan penurunan makin kecil. Dengan demikian metode ini mempunyai hasil utama berupa pemberian ketahan gelincir dan hasil sampingan yaitu jumlah total penurunan berkurang ddan mempunyai batasan deformasi geser.

\section{Metode Timbunan Imbangan Berat}

Dapat dilihat, bahwa pengaruh metode ini adalah untuk mencegah timbunan terhadap gelincir dengan membuat imbangan berat pada sisi timbunan dan meningkatkan momen penahan guna melawan gelincir yang terjadi sehingga membuat permukaan lebih landai. Metode ini hanya menghasilkan pemberian ketahanan gelincir dan batasan deformasi geser sebagai hasil sampingannya.

\section{Metode Pembebanan}

Pada metode pembebanan ini terlihat bahwa tekanan efektif tanah meningkat, demikian juga dengan lembaran tipis yang kedap udara akan meningkatkan tekanan atmosfir. Jadi hasil utama pada metode ini adalah timbulnya penurunan karena konsolidasi dan naiknya tekanan efektif. 


\section{Metode Drainasi Vertikal}

Metode kolam pasir ditempatkan pada jarak tertentu sesuai dengan kadar air tanah, permeabilitas dan ukuran butiran yang diletakkan secara vertikal sehingga dapat mengurangi drainasi konsolidasi dan penurunan akibat konsolidasi yang merupakan pengaruh utama dan juga dapat menaikkan tekanan efektif yang merupakan pengaruh hasil sampingan bersamaan dengan batasan deformasi.

\section{Tiang Pasir Padat}

Dengan adanya tiang-tiang pasir yang termanpatkan ini akan mempengaruhi pemadatan lapisan lunak tanah pondasi. Pada saat yang sama akan meningkatkan daya dukung tanah secara keseluruhan yang akan mengurangi penurunan. Disini hasil utama yang dapat diperoleh yaitu jumlah total pengurangan penurunan, pemberian ketahanan gelincir dan pencegahan terhadap liquefaction sedangkan hasil sampingnya yaitu timbulnya penurunan karena konsolidasi dan batasan deformasi geser.

\section{Metode Tiang kapur}

Dari uraian di atas terlihat pengaruh metode ini berupa pada penyerapan air oleh adanya tiang kapur. Kemantapan meningkat dengan bertambahnya kekuatan tanah pondasi dan bersamaan dengan itu penurunan berkurang, sehingga hasil utama yang diperoleh adalah jumlah total pengurangan penurunan dan pemberian ketahanan gelincir, sedangkan hasil sampingnya tidak ada.

\section{Metode Pencampuran Lapisan Dalam}

Pengaruh metode ini dengan stabilisator semen yang dikocok dan dicampur dengan tanah kohesif yang akan mengkonsolidasikan laposan tanah pondasi. Hasil utama yang diperoleh adalah jumlah total pengurangan penurunan, batasan deformasi geser dan pemberian ketahanan gelincir sedangkan hasil sampingnya tidak ada. 
Untuk setiap metode pelaksanaan dan pengaruhnya adalah seperti tabel berikut:

Tabel : Pengaruh Metode

\begin{tabular}{|c|c|c|c|c|c|c|c|c|}
\hline No & $\begin{array}{c}\text { Metode } \\
\text { Pelaksanaan }\end{array}$ & $\begin{array}{l}\text { Timbulnya } \\
\text { Penurunan } \\
\text { konsolidasi }\end{array}$ & $\begin{array}{c}\text { Jumlah total } \\
\text { pengurangan } \\
\text { penurunan }\end{array}$ & $\begin{array}{c}\text { Batasan } \\
\text { deformasi } \\
\text { geser }\end{array}$ & $\begin{array}{c}\text { Batasan } \\
\text { pengurangan } \\
\text { kekuatan }\end{array}$ & $\begin{array}{c}\text { Timbulnya } \\
\text { kenaikan } \\
\text { kekuatan } \\
\text { efektif }\end{array}$ & $\begin{array}{l}\text { Pemberian } \\
\text { ketahanan } \\
\text { gelincir }\end{array}$ & $\begin{array}{l}\text { Pencegahan } \\
\text { terhadap } \\
\text { liquefaction }\end{array}$ \\
\hline 1 & $\begin{array}{l}\text { Perbaikan } \\
\text { permukaan }\end{array}$ & & & $\square$ & $\Delta$ & $\Delta$ & $\Delta$ & $\Delta$ \\
\hline 2 & Perpindahan & & $\Delta$ & $\Delta$ & & & $\square$ & \\
\hline 3 & Imbangan berat & & & $\Delta$ & & & & \\
\hline 4 & Pembebanan & $\square$ & & & & $\Delta$ & & \\
\hline 5 & $\begin{array}{l}\text { Drainase } \\
\text { vertikal }\end{array}$ & $\square$ & & $\Delta$ & & $\Delta$ & & \\
\hline 6 & $\begin{array}{l}\text { Tiang pasir } \\
\text { padat }\end{array}$ & $\Delta$ & $\square$ & $\Delta$ & & & $\square$ & $\square$ \\
\hline 7 & Tiang kapur & & $\square$ & & & & $\square$ & \\
\hline 8 & $\begin{array}{l}\text { Pencampu-ran } \\
\text { lapisan dalam }\end{array}$ & & $\square$ & $\square$ & & & $\square$ & \\
\hline
\end{tabular}

$\square=$ Hasil Utama

$\Delta=$ Hasil Sampingan

\section{Analisis Sintesis}

Dari tabel dapat dilihat, bahwa tiang pasir padat (6) dan pencampuran laposan dalam (8) mempunyai tiga macam hasil utama, masing-masing adalah jumlah total pengurangan penurunan, pemberian ketahanan gelincir, serta pencegahan terhadap liquefaction untuk tiang pasir padat (6) dan batasan deformasi geser untuk pencampuran lapisan dalam (8). Sedangkan metode tiang kapur (7) mempunyai dua hasil utama dan metode lainnya, hanya satu hasil utama.

Demikian juga untuk hasil sampingan dimana tiang pasir padat (6) mempunyai dua hasil sampingan, dua hasil sampingan untuk metode perpindahan (2), dan dua hasil simpangan untuk drainase vertikal (5). Hasil sampingan yang terbanyak adalah metode perbaikan permukaan (1) yaitu batasan pengurangan kekuatan, timbulnya kenaikan, pemberian ketahanan gelincir dan pencegahan terhadap liquefaction. Sedangkan yang paling sedikit memberi pengaruh metode adalah metode timbangan berat (3) dan metode pembebanan (4) masing-masing mempunyai 1 hasil sampingan.

Berdasarkan pengaruh metode yang dihasilkan dari setiap metode pada tabel di atas maka dapat diketahui bahwa setiap metode berbeda-beda tetapi metode yang paling 
baik adalah metode tiang pasir padat karena menghasilkan tiga hasil utama yaitu jumlah total pengurangan penurunan, pemberian ketahanan gelincir, dan pencegahan terhadap liquefaction. Dan juga menghasilkan dua hasil sampingan yaitu timbulnya penurunan karena dan batasan deformasi geser.

\section{KESIMPULAN}

1. Metode tiang pasir padat (6) adalah yang paling baik diantara semua metode yaitu mempunyai tiga hasil utama ditambah hasil sampingan, seperti jumlah total pengurangan penurunan, pemberian ketahanan gelincir, dan pencegahan liquefaction.

2. Metode pencampuran lapisan adalah yang kedua paling baik dengan tiga hasil utama yaitu jumlah total pengurangan penurunan, batasan deformasi geser, dan pemberian ketahanan gelincir.

3. Metode yang paling tidak menguntungkan atau menghasilkan pengaruh metode yang kecil adalah metode imbangan berat (3) dan metode pembebanan (4).

\section{DAFTAR PUSTAKA}

Aziz Jaya Putra (HATTI), Perbaikan Tanah Lunak

Berelson, B, 1952, Conten Analysis in Communication Research,: Free Press, New York

Bowles, J.E., 1989, Sifat-sifat dan Geoteknik Tanah, Terjemahan, Erlangga, Jakarta

Craig, R.F., 1991, Mekanika Tanah, Terjemahan, Erlangga, Jakarta

George Geoffrey Mayerhof, 1981, The Bearing Capacity and Settlement of Foundation's,

Glaser and Stranss, 1980, The Discovery of Grounded Theory : Strategis for Qualitative Research, , Aldine Publishing, Co, New York

Gouw Thie Liong, Perbaikan Tanah dengan Cara Dinamis dan Statis dengan Geosinteti 